\title{
Magnitude and factors associated with adherence to Iron-folic acid supplementation among pregnant women in Eritrean refugee camps, northern Ethiopia
}

\author{
Mekdemariam Getachew ${ }^{1}$, Mebrahtu Abay ${ }^{2 *}$ (D) Hiwet Zelalem³ ${ }^{3}$ Tirhas Gebremedhin², Teklit Grum² \\ and Alemayehu Bayray ${ }^{4}$
}

\begin{abstract}
Background: Globally, anemia is a public health problem affecting the life of more than two billion people. Pregnant women are at high risk of iron deficiency anemia due to increased nutrient requirement during pregnancy. Iron-folic acid supplementation is the main strategy for prevention and control of iron deficiency anemia and its effectiveness depends on adherence to Iron-Folic Acid tablets. In the refugee camps of Ethiopia, despite the efforts made to reduce iron deficiency anemia during pregnancy, information about adherence to iron-folic acid supplementation and its associated factors are lacking. The objective of this study was to assess magnitude and factors associated with adherence to iron-folic acid supplementation, among pregnant women, in Shire refugee camps.

Methods: Institution based cross-sectional study with mixed design (quantitative and qualitative) was carried out among pregnant women in Shire refugee camps from September to November 2015. For quantitative data, a sample of 320 pregnant women was systematically selected and data were collected via interview administered structured questionnaire. Quantitative data were coded and entered into Epi-info version 3.5.1 and exported into a statistical package for social sciences (SPSS) Version 19.0 software for analysis. Bivariable and multivariable logistic regressions were employed to identify the predictors at $p$-value $<0.2$ and 0.05 respectively. For the qualitative part, six focus group discussions and three key informant interviews were conducted on purposely-selected individuals. Open-Code version 3.6.2.0 was used for analysis. Identified themes were arranged into coherent groupings and triangulated with quantitative findings.
\end{abstract}

Results: The adherence rate was found to be $64.7 \%$ [95\% Cl $(59.7 \%, 70.0 \%)]$. Women who were having lower knowledge about anemia [AOR; $0.2395 \% \mathrm{Cl}(0.14,0.38)]$ and not receiving information about importance of iron-folic acid supplementation [AOR; $0.4395 \% \mathrm{Cl}(0.25,0.74)$ ] were negatively associated with adherence to iron and folic acid., Having four or more antenatal care visits [AOR; $2.8395 \% \mathrm{Cl}(1.46,5.48)]$ were positively significantly associated with adherence to iron-folic acid supplementation.

(Continued on next page)

\footnotetext{
* Correspondence: gmebrahtuabay@gmail.com

2Department of Public Health, College of Health Sciences, Aksum University,

P.O. Box: 298, Aksum, Ethiopia

Full list of author information is available at the end of the article
} 
(Continued from previous page)

Conclusions: Adherence rate of iron-folic acid supplementation during pregnancy in the study area is relatively low. Proper counseling and health promotion about Iron-Folic Acid tablet intake, promoting the benefits of early and frequent ANC visit, health promotion on anemia prevention and health benefits of the importance of iron-folic acid supplements are recommended to increase adherence with iron-folic acid supplementation.

Keywords: Adherence, Iron-folic acid supplementation, Anemia, Pregnant women, Eritrean refugee camps, Ethiopia

\section{Background}

Globally, almost $41.8 \%$ of pregnant women and $30.2 \%$ non-pregnant women are anemic $[1,2]$. In addition, $20 \%$ of maternal mortality in Sub-Saharan Africa is directly attributable to anemia [1]. In Ethiopia, 17\% of reproductive age group women and $22 \%$ of pregnant women are anemic. When we look at the residence difference the magnitude of anemia among pregnant women who reside in rural and urban areas is $18 \%$ and $11 \%$, respectively [3].

In several low-income countries, the cause of anemia during pregnancy is multi-factorial. It includes nutritional deficiencies of iron, folic acid, vitamin B-12 and parasitic diseases such as malaria and hookworm. In sub-Saharan Africa, iron and folic acid deficiencies are the most common causes of anemia among pregnant women [4].

Iron deficiency anemia contributes to adverse effects on maternal and child health. The maternal consequences of anemia, which include, but not limited to, low weight gain, preterm labor, placenta previa, premature rupture of membrane, cardiac arrest, hemorrhage, lowered resistance to infection, poor cognitive development, and reduced work capacity. Similarly, anemia during pregnancy has fetal and neonatal risks, which include prematurity, low birth weight, and fetal distress, which contribute to perinatal morbidity and mortality. Infants born to anemic women are more likely to become anemic themselves $[5,6]$. Folic acid deficiency at conception and in early pregnancy is also associated with increased risk of neural tube defect, preeclampsia, fetal malformations and preterm delivery $[7,8]$.

In Ethiopia, iron-folic acid supplementation (IFA) is one of the main strategies for prevention of anemia. The Ethiopian national guideline for prevention of micronutrient deficiencies highlights the need for daily IFA supplementation for at least 6 months during pregnancy and 3 months postpartum [9]. But, effectiveness and success of such interventions depend on the adherence to IFA tablets. Adherence describes the degree to which a patient correctly follows a medical advice. Many experts believe that one of the main reasons that national iron supplementation programs have failed is women's "noncompliance" [10, 11].
In spite of the WHO recommendation, the use of iron and folic acid supplementation is still low in many countries [12]. According to the Ethiopia Demographic Health Survey (EDHS) of 2011, less than 1\% of pregnant women took IFA supplement for recommended period during their pregnancy; but this prevalence might not be exactly comparable with the aim of this study, which is conducted among pregnant women with full availability of IFA, as availability is a pre-requisite for utilization [3]. A study in four major regions of Ethiopia (Tigray, Amhara, Oromiya, and Southern Nations Nationalities and Peoples shows fewer than 3.5\% took the supplements for more than 90 days [13].

The aim of this study was, therefore, identifying the magnitude of anemia and its determinants among pregnant women in Shire refugee camps, Ethiopia.

\section{Methods \\ Study setting}

Health facility-based cross-sectional study was carried out in four Shire refugee camps, named as "Shimelba", "May-Aini", "Adi-Harush", and"Hitsats", located in the Tigray regional state, Northern Ethiopia whereby Eritrean refugees are residing in. According to the UNHCR monthly population data, the Eritrean refugee population in the four camps was 60,119 as of 31 December 2013, of which $28.1 \%$ were females.

Data were collected from 03, November to 29, December 2015, and 1036 pregnant women were residing during the data collection period in all refugee camps.

Each refugee camp had one health center, which is administered by the Administration for Refugees and Returnees Affairs (ARRA). Comprehensive health services and nutrition programs are running in the four camps supported by UNHCR and WFP. Maternal health services have been implemented in each refugee camp. Pregnant women who came to the health centers had an access to all components of ANC services including IFA supplementation by health social workers regularly.

\section{Population and sampling}

The source population was pregnant women residing in all of the four Shire refugee camps. The pregnant women visiting Shire refugee camps' health centers at least for a second antenatal visit and received IFA tablets 
for at least one month prior to the date of interview were selected as the study population. Women who were critically ill during the data collection period were excluded from the study. The interview was made just before receiving the ANC service.

\section{In quantitative part}

A total of 320 pregnant women were included in the study. The sample size was calculated using a single population proportion formula with the proportion of adherence $(P=37 \%)$ from a study conducted in North West Tigray [14]. During the sample size calculation, the assumptions of $95 \%$ confidence interval, $5 \%$ of marginal error and $10 \%$ non-response rate were considered. To determine the number of women to be interviewed, an average of 12 months' flow of pregnant women in each camp was obtained from UNHCR and ARRA Health Information System (HIS) report. The average number of pregnant women attending second ANC visit in each health center was; 267 in "Shimelba", 214 in "May-Aini", 161 in "Adi-Harush" and 394 in "Hitsats". Considering the client flow in the health center, the total sample size determined (320) was allocated proportionally to each health center in the camps (Fig. 1). The final sample from each camp was done consecutively until we reach the required sample.

\section{In qualitative part}

A total of six Focus Group Discussions (FGDs) among pregnant women and three Key Informant Interviews (KIIs) among midwives who give ANC service for the pregnant women in the four refugee camps were conducted using purposive sampling technique until enough information is gained. A total of 56 participants were involved in the six FGDs. The average number of participants in the FGDs was 10 individuals with a range of 8 to 12 individuals. One to two FGDs were conducted in each of the four refugee camps, and pregnant women were selected purposefully based on their length of pregnancy period. To get sufficient information pregnant women with longer duration of pregnancy, usually in their third trimester, were selected.

\section{Data collection and quality assurance procedures For the quantitative part}

Structured questionnaires were used for the interview. The questionnaire was adopted and modified from Ethiopian Health and Nutrition Research Institute, micronutrient initiative effective modalities to improve pregnant women's adherence to daily iron supplementation survey questionnaire, WHO guideline for anemia prevention and other literature $[15,16]$. First, the questionnaire was written in English and then translated to the local language, Tigrigna, peer-reviewed and translated back to English to ensure consistency. The Tigrigna version of the questionnaire was pretested among 16 women (5\% of the total sample size) who visit May-Tsebri government health center Maternal and Child Health $(\mathrm{MCH})$ clinic. The principal investigator and data collectors undertook the pretest. Based on the findings of the pretest, necessary corrections and amendments were made on the questionnaire before the actual data collection was started. Four refugee diploma holder midwife data collectors (one for each camp) and two supervisors (one for two camps) who have a Bachelor of Science in nursing were recruited. Supervisors and data collectors had previous experience of data collection and were trained for one day (See Additional file 1 for details of the quantitative data collection tool).

\section{For the qualitative part}

FGD interview guide note was used to understand the perceptions of participants about the use of antenatal IFA supplementation. Furthermore, the behavioral and cultural issues in terms of facilitating factors and barriers to utilization of antenatal IFA supplementation were

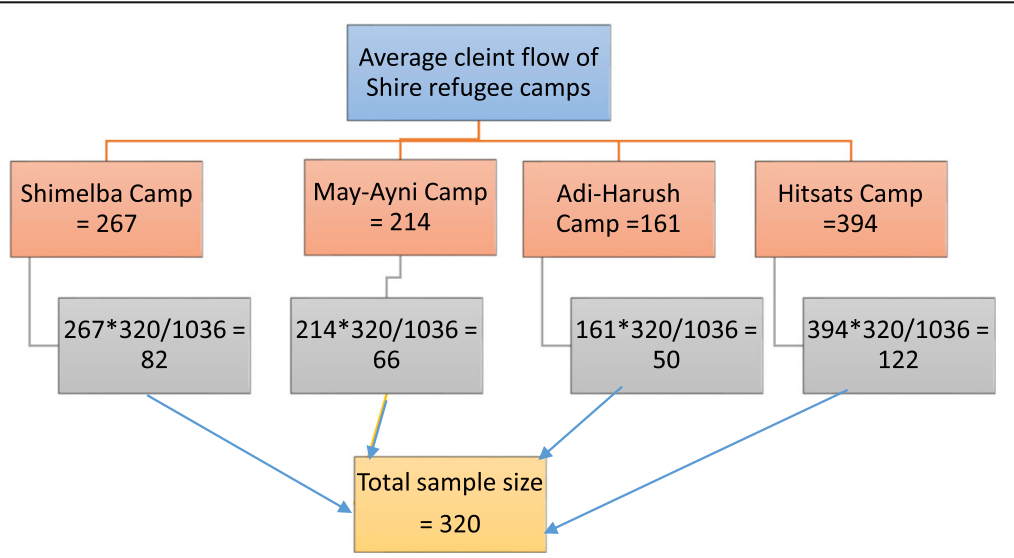

Fig. 1 Sampling procedure for the quantitative data among pregnant women in Eritrean refugee camps, northern Ethiopia 
assessed through KII guiding questions. First, the FGD guiding questions were written in English and then translated to the local language, Tigrigna, and peerreviewed and then translated back to English before administration. Two bachelor degree holders in nursing and sociology with experiences in collecting qualitative data were assigned in each FGD to collect data as modulator and note taker. A tape recorder was used to capture the qualitative data during FGD and KII. Key informant interview was administered by the principal investigator and one bachelor holder in nursing was a note taker (see Additional file 2 for details of the qualitative data collection tool).

\section{Variables and measurement}

The dependent variable is adherence to iron-folic acid supplementation and the independent variables are socio-demographic, obstetric, personal/individual and health service related factors of the pregnant women.

\section{Adherence to IFA}

Pregnant women who reported that they took at least $70 \%$ of the expected dose of the IFA tablets in the previous two weeks before the data collection, which is equivalent to consuming at least five tablets per week, were considered as adhered to IFA supplementation, and the opposite is true for non-adherence $[15,17,18]$. All women had given sufficient IFA tablets during their first and second ANC visit. Regarding the monthly income of the respondents, a tertile classification is applied to categorize it into three levels, as low, medium and higher income categories.

\section{Knowledge about anemia}

To assess the level of knowledge about anemia during pregnancy, respondents were asked 18 questions on major causes, symptoms, and consequences during pregnancy. Those who scored $>$ the mean value were considered as somehow knowledgeable and those who scored $\leq$ the mean value were considered as less knowledgeable.

\section{Data management and analyses procedures \\ For the quantitative part}

Data were coded and entered into Epi-info version 3.5.1 and exported into statistical package for social sciences (SPSS) Version 21.0 software for analyses. Descriptive statistics were employed to describe the study population in relation to socio-demographic and other relevant variables and to display findings in mean, median, percentage and $95 \%$ confidence intervals. A composite scale was constructed for maternal knowledge about anemia. To identify factors associated with adherence to IFA supplementation, first a bivariable logistic regression was performed for each independent variable with adherence to IFA supplementation and crude odds ratio with 95\% confidence intervals was obtained. Subsequently, significant variables in the bivariable analysis $(p$-value $<0.2)$ were incorporated into the multivariable logistic regression to determine independent predictors of adherence to IFA supplementation among pregnant women. To control the effect of the four different health facilities (camps), a random effect was estimated using Generalized Estimating Equation (GEE) model. Results were summarized using tables, figures and graphs. The goodness of fit of the final logistic model was tested using Hosmer and Lemeshow test. For the knowledge-related questions, reliability was checked during pretest using Cronbach's Alpha, which was 0.746 .

\section{For the qualitative part}

Open code version 3.6.2.0 software was used for analysis. Data were recorded by tape recorders from six FGDs and three KIIs were transcribed word-by-word into plain text and translated into English. After codes were developed, issues discussed and themes developed. The codes developed from the texts were coded into the following terms: availability of tablets, knowledge about IFA supplementation, attitude about IFAs, information from health professionals, and the perception of women, as they are healthy, parity and gravidity. The themes developed from the codes were personal factors, health facility-related factors, and pregnancy-related factors. All authors together develop the codes and themes of the qualitative data. An MSc expert in Health Education assisted how to analyze the qualitative data. Finally, the themes were triangulated with quantitative findings.

\section{Results}

\section{Demographic and socioeconomic characteristics of respondents}

A total of 320 pregnant women were interviewed with a $100 \%$ response rate. The mean age of the study subjects was $26.7(\mathrm{SD}=5.95)$ years. A majority, $257(80.3 \%)$ of the respondents was between 20 and 34 years of age. More than half, $193(60.3 \%)$ of the respondents were Orthodox Christian by religion. A significant number of respondents, $65(20.3 \%)$, were unable to read and write. Regarding their occupational status, 255 (79.7\%) were housewives. In this study $199(62.2 \%)$ of respondents had an average household monthly income of above 900 Ethiopian Birr (> 40.7 USD) (Table 1).

\section{Obstetric and health service related characteristics of respondents}

The mean gestational age of the pregnant women was $30.8(\mathrm{SD}= \pm 4.4)$ weeks. The majority of the participants were in their third trimester 205 (64.1\%). The mean gestational age of pregnant women started taking IFA 
Table 1 Socio-demographic characteristics of pregnant women attending antenatal clinics in Shire refugee camps, Tigray, Ethiopia, 2015. $(n=320)$

\begin{tabular}{|c|c|c|c|}
\hline Variables & & Number & Percent \\
\hline \multirow[t]{3}{*}{ Age in years } & $15-19$ & 25 & 7.8 \\
\hline & $20-34$ & 257 & 80.3 \\
\hline & $>34$ & 38 & 11.9 \\
\hline \multirow[t]{4}{*}{ Religion } & Orthodox & 193 & 60.3 \\
\hline & Muslim & 56 & 17.5 \\
\hline & Catholic & 49 & 15.3 \\
\hline & Protestant & 22 & 6.9 \\
\hline \multirow[t]{3}{*}{ Marital status } & Single & 29 & 9.1 \\
\hline & Married & 283 & 88.4 \\
\hline & Divorced & 8 & 2.5 \\
\hline \multirow[t]{4}{*}{ Maternal occupation } & House wife & 255 & 79.7 \\
\hline & Merchant & 21 & 6.6 \\
\hline & Volunteer & 21 & 6.6 \\
\hline & Others $^{*}$ & 23 & 7.2 \\
\hline \multirow[t]{3}{*}{ Maternal education } & $\begin{array}{l}\text { Unable to read } \\
\text { and write }\end{array}$ & 65 & 20.3 \\
\hline & $\begin{array}{l}\text { Primary education } \\
\text { completed }\end{array}$ & 163 & 50.9 \\
\hline & $\begin{array}{l}\text { Secondary and } \\
\text { above }\end{array}$ & 92 & 28.8 \\
\hline \multirow[t]{3}{*}{ Husband education } & $\begin{array}{l}\text { Unable to read } \\
\text { and write }\end{array}$ & 25 & 8.8 \\
\hline & $\begin{array}{l}\text { Completed primary } \\
\text { education }\end{array}$ & 114 & 40.3 \\
\hline & $\begin{array}{l}\text { Secondary and } \\
\text { above }\end{array}$ & 144 & 50.9 \\
\hline \multirow[t]{3}{*}{ Family size } & $1-3$ & 146 & 45.6 \\
\hline & $4-6$ & 142 & 44.4 \\
\hline & $>6$ & 32 & 10.0 \\
\hline \multirow{3}{*}{$\begin{array}{l}\text { Monthly income in } \\
\text { Ethiopian Birr (US Dollar) }\end{array}$} & $<500(\leq 22.6)$ & 54 & 16.9 \\
\hline & $500-900(22.6-40.7)$ & 67 & 20.9 \\
\hline & $>900(>40.7)$ & 199 & 62.2 \\
\hline
\end{tabular}

Others*: daily laborer, farmer

supplement were at 17.1 $(\mathrm{SD}= \pm 4.4)$ week. More than half of the women were gravida 2-4 [183 (57.2\%)] and para-1 [159 (55.9\%)]. Only 32 (10\%) of the pregnant women had known medical illness at the time of interview (Table 2).

\section{Adherence to IFA supplementation of the respondents}

Adherence level was determined by self-report questions among 320 women who were given iron-folic acid supplements during pregnancy. Only 207 [64. $7 \%$; 95\% CI $(59.7,70.0)]$ women took $\geq 70 \%$ of expected doses of the IFA supplements, that is, for greater than five days in a week. The primary
Table 2 Obstetric and health service related characteristics of pregnant women attending antenatal clinics in Shire refugee camps, Tigray, Ethiopia, 2015. $(n=320)$

\begin{tabular}{|c|c|c|c|}
\hline Variables & & Number & Percent \\
\hline \multirow[t]{3}{*}{ Gravida (number of pregnancies) } & 1 & 78 & 24.4 \\
\hline & $2-4$ & 183 & 57.2 \\
\hline & $>=5$ & 59 & 18.4 \\
\hline \multirow[t]{4}{*}{ Parity (number of deliveries) } & 0 & 78 & 24.4 \\
\hline & 1 & 171 & 31.5 \\
\hline & $2-4$ & 116 & 53.4 \\
\hline & $>=5$ & 25 & 7.8 \\
\hline \multirow[t]{3}{*}{ Birth order } & 1 & 179 & 55.9 \\
\hline & $2-4$ & 116 & 36.3 \\
\hline & $>=5$ & 25 & 7.8 \\
\hline \multirow{2}{*}{$\begin{array}{l}\text { Pregnancy Trimester } \\
\text { during interview }\end{array}$} & Second trimester & 115 & 35.9 \\
\hline & Third trimester & 205 & 64.1 \\
\hline \multirow{2}{*}{$\begin{array}{l}\text { Gestational Age where } \\
\text { ANC started }\end{array}$} & Before 16 weeks & 154 & 48.1 \\
\hline & $\begin{array}{l}\text { At or After } \\
16 \text { weeks }\end{array}$ & 166 & 51.9 \\
\hline \multirow[t]{2}{*}{ Number of ANC visits } & $2-3$ & 232 & 72.5 \\
\hline & $\geq 4$ & 88 & 27.5 \\
\hline \multirow{2}{*}{$\begin{array}{l}\text { Receiving information about } \\
\text { the importance of IFA } \\
\text { supplementation }\end{array}$} & No & 139 & 43.4 \\
\hline & Yes & 181 & 56.6 \\
\hline \multirow[t]{2}{*}{ Medical illness } & No & 288 & 90.0 \\
\hline & Yes & 32 & 10.0 \\
\hline \multirow[t]{2}{*}{ Morning sickness } & No & 255 & 79.7 \\
\hline & Yes & 65 & 20.3 \\
\hline \multirow[t]{2}{*}{ Side effects } & No & 234 & 83.1 \\
\hline & Yes & 86 & 26.9 \\
\hline
\end{tabular}

underlying reasons for the non-adherence of IFA among the pregnant women were, occurrence of side effects [86 (40\%)], unaware of the importance of IFA [65 (30.2\%)], forgetfulness [31 (14.4\%)], inadequate or lack of IFA in health facility [26 (12.1\%)] and fear of side effects [7 (3.3\%)].

This was supported by the FGD. Most of FGD participants reported that forgetfulness and drug side effects are the main reasons for non- adherence. "I want to take the IFA supplementation as prescribed, but I repeatedly forget to take the tablet regularly." (A 27 years old, pregnant woman participated in FGD). "All drugs, including the drugs used to prevent anemia, are very important, but the problem is that it is very difficult to take them continuously, as they have their own side effect; otherwise I believe that they are very important to our health." (A 25 years old pregnant woman participated in the FGD). 
Knowledge of respondents about anemia during pregnancy Of the total participants, 261 (81.6\%) had ever heard of anemia during pregnancy. Comprehensive knowledge of anemia was computed by summing up all relevant 18 knowledge items. The mean score was $7.7(\mathrm{SD}=4.23)$. Accordingly, $61.3 \%$ of the respondents were somehow knowledgeable about anemia. This was supported by the FGD; most of the pregnant women mentioned fatigue, dizziness, swelling in the extremities as major sign and symptom. The risk of maternal death during labor and fetal growth retardation are also reported as consequences of anemia during pregnancy.

"I myself have anemia. I feel dizzy and weak." (A 35-year old pregnant women having five children participated in FGD).

Factors associated with adherence to IFA supplementation In the bivariable analysis, seven factors were found to be significantly associated with adherence to IFA supplementation. Maternal age $[\mathrm{COR}=2.39,95 \% \mathrm{CI}=(0.87-6$. 56)], merchants $[\mathrm{COR}=1.88,95 \% \mathrm{CI}=(1.29-2.61)]$, farmers/daily laborers $[\mathrm{COR}=2.69,95 \% \mathrm{CI}(1.13-6.40)]$ number of ANC visits $[\mathrm{COR}=0.31,95 \% \mathrm{CI}=(0.17-0.56)]$, time of ANC visit in trimester $[\mathrm{COR}=0.47,95 \% \mathrm{CI}=(0$. $30-0.76)]$, reported morning sickness $[\mathrm{COR}=0.65,95 \%$, $\mathrm{CI}=(0.35-1.18)]$, receiving information about importance of IFA supplementation $[\mathrm{COR}=0.29,95 \% \mathrm{CI}=(0.18-0$. $47)]$ and maternal knowledge about anemia $[\mathrm{COR}=0$. 25 , 95\% $\mathrm{CI}=(0.14-0.43)]$ at $P$-value of $<0.2$. Ultimately, frequency of ANC visit, receiving information about the importance of iron supplementation and maternal knowledge about anemia were identified as significant independent predictors in the multivariable logistic regression analysis after adjusting to each other at $(P$-value $<0.05)$.

Therefore, controlling all other variables, having less knowledge about anemia during pregnancy was negatively associated with adherence to IFA supplementation [AOR $=\mathbf{0 . 2 5}, \mathbf{9 5 \%} \mathrm{CI}=\mathbf{( 0 . 1 4 - 0 . 4 3 )}]$. Not receiving information about the importance of IFA supplementation during pregnancy was negatively associated with adherence to IFA $[\mathrm{AOR}=\mathbf{0 . 4 3}, \mathbf{9 5} \% \mathrm{CI}=\mathbf{( 0 . 2 5 - 0 . 7 4 )}]$. ANC visit of four times or more was positively related to adherence to IFA supplement $[$ AOR $=\mathbf{2 . 8 3}$, 95\% CI = (1.46-5.48)] (Table 3).

These findings are supported by the FGDs and KIIS. Most of FGD's participants reported that ANC is important for every mother to prevent different diseases and to have a healthy baby and visit should be started as early as possible. The majority of the respondents were able to describe the supplements and report the benefits of the supplements as to prevent anemia, replace blood and better fetal health. "I believe that being followed by a doctor continuously is good to early detect any problem during pregnancy so that it could be managed as early as possible". (A 30-year old pregnant women having three children participated in FGD). All participants argued that should be taken once daily and continued throughout pregnancy.

\section{Discussion}

In this study, 64.7\%, with 95\% CI (59.7\% -70.0\%), of pregnant women were found to be compliant with IFA. This finding is consistent with studies done in different regions of Nigeria (65.9\%), Senegal (69\%), India (64.7\%) and Philippines (70\%) $[13,14,19,20]$. But it is a little bit lower as compared to the comparative study done in North Western Zone of Tigray, Ethiopia which revealed that $74.9 \%$ [15]. This finding is also inconsistent with the study done in Amhara region of Ethiopia which revealed that $20.4 \%$ adherence rate [20]. The probable reason may be their difference in living situation and the time gap between studies and study subjects. The reported level of adherence to IFA (64\%) might have been overestimated because the measurements are via self-reporting method [15].

The number of ANC visits has a significant effect on adherence with IFA supplementation. ANC is a crucial channel for supplementing iron and folic acid during pregnancy. Therefore, the observed relationship between the level of ANC service utilization and level of IFA utilization is as expected. This finding is consistent with studies conducted in North Western Zone of Tigray, Ethiopia $\quad(\mathrm{AOR}=3.784, \quad 95 \% \quad \mathrm{CI}=2.073-6.909) \quad$ and Philippines $(R=250.233$, P, 0.01) [15, 20]. The reason might be that health providers could help women during their ANC visits by discussing adherence to IFA supplement, encouraging them to take the tablet as prescribed, and educating them on health benefit of taking IFA supplement. This result might be linked to the fact that women who receive health education about adherence to iron and folic acid by the health professionals during their regular follow-up period.

This study revealed that women who are more or less knowledgeable on anemia were more likely to be adherent with IFA. This is consistent with studies done in Nigeria and Ethiopia [13, 15, 17, 20]. Pregnant women who received information about the importance of iron supplementation during pregnancy were more likely to be compliant than those who were not. This is consistent with studies done in India and Sudan [16, 19].

Findings from the qualitative study revealed that forgetting to take drugs and fear of side effects are among the common reasons for lack of adherence to IFA in this study. Health professionals in charge of ordering IFA during pregnancy should apply detail counseling about the possible mild side effects of the drug and convince them that these side effects are limited and self-managed. 
Table 3 Factors associated with adherence to IFA supplementation among pregnant women attending antenatal clinics in Shire refugee camps, Tigray, Ethiopia, 2015. $(n=320)$

\begin{tabular}{|c|c|c|c|c|c|}
\hline \multirow[t]{2}{*}{ Variables } & & \multicolumn{2}{|c|}{ Adherence for IFA supplementation } & \multirow[t]{2}{*}{ COR (Cl 95\%) } & \multirow[t]{2}{*}{ AOR (CI 95\%) } \\
\hline & & Yes & No & & \\
\hline \multirow[t]{3}{*}{ Age } & $15-19$ & 20 & 5 & 1.00 & 1.00 \\
\hline & $20-34$ & 161 & 96 & $2.39(0.87-6.56)$ & $3.09(1.02-9.40)$ \\
\hline & $>35$ & 26 & 12 & 1.85(0.56-6.10) & 2.60(0.68-9.88) \\
\hline \multirow[t]{4}{*}{ Maternal occupation } & House wife & 172 & 83 & 1.00 & 1.00 \\
\hline & Merchant & 11 & 10 & 1.88(0.77-0.61) & 0.83(0.29-2.36) \\
\hline & Volunteer & 14 & 7 & 1.04(0.40-2.66) & $0.76(0.27-2.15)$ \\
\hline & Others $^{a}$ & 10 & 13 & $2.69(1.13-6.40)$ & $0.59(0.22-1.58)$ \\
\hline \multirow[t]{2}{*}{ Time of ANC started } & $<16$ weeks of GA & 41 & 113 & 1.00 & 1.00 \\
\hline & $\geq 16$ weeks of $G A$ & 72 & 94 & $0.47(0.30-0.76)$ & $0.87(0.50-1.50)$ \\
\hline \multirow[t]{2}{*}{ Number of ANC visit } & $<4$ visits & 97 & 135 & 1.00 & 1.00 \\
\hline & $\geq 4$ visits & 16 & 72 & $0.31(0.17-0.56)$ & $2.83(1.46-5.48)^{\mathrm{b}}$ \\
\hline \multirow[t]{2}{*}{ Received information on importance of IFA } & Yes & 42 & 139 & 1.00 & 1.00 \\
\hline & No & 71 & 68 & $0.29(0.18-.47)$ & $0.43(0.25-0.74)^{\mathrm{b}}$ \\
\hline \multirow[t]{2}{*}{ Morning sickness } & No & 160 & 95 & $0.65(0.35-1.18)$ & $1.79(0.89-3.58)$ \\
\hline & Yes & 47 & 18 & 1.00 & 1.00 \\
\hline \multirow[t]{2}{*}{ Knowledge on Anemia during Px. } & Somehow knowledgeable & 69 & 55 & 1.00 & 1.00 \\
\hline & less knowledgeable & 44 & 152 & $0.25(0.14-0.43)$ & $0.23(0.14-0.38)^{\mathrm{b}}$ \\
\hline
\end{tabular}

Others $^{\mathrm{a}}$ : Farmer, daily laborer

${ }^{\mathrm{b}}$ Significant association at $95 \%$ confidence level

Px pregnancy, COR Crude Odds Ratio, AOR Adjusted Odds Ratio, Cl Confidence Interval, GA Gestational Age, ANC Antenatal Care

Regarding the issue how to minimize forgetfulness, women should be continuously counseled to use different mechanisms like correlating with natural occurrences, sunrise or sunset, lunch or dinner, toilet use or hand washing so on and so forth.

Beside to fear of side effects and forgetfulness to take the drugs, which are factors found to be significant barriers for poor adherence of IFA in this study, negative perception about the drug, like fear of fetal complications and fear of making delivery more difficult are another factors found by different researchers so far $[15,21-23]$.

\section{Limitation of the study}

This study has its own limitations. One of the limitations of this paper is the adherence level of the iron and folic acid among the pregnant women is simply determined by a self-report mechanism (the women's response). This might affect the actual adherence level of the target population. Not all potential barriers to IFA adherence had been investigated and the measurement of the knowledge level of respondents about IFA is somehow subjective.

\section{Conclusions}

The magnitude of adherence to IFA supplementation during pregnancy is relatively low in the refugee camps.
This points out that the WHO and FMOHE recommendations were not met despite the fact that IFA supplementation program during pregnancy is used to prevent iron deficiency anemia during pregnancy.

The study finds out that counseling on IFA supplementation, knowledge of women on anemia and number of ANC visit were factors significantly associated with adherence to IFA supplementation during pregnancy. Both the quantitative and the qualitative results support that there are many barriers to adherence of IFA among pregnant mother like forgetfulness, drug side effects, and fear of side effects were the leading underlying reasons among women with low adherence. It is therefore crucial that pregnant women in the refugee camps should be given more focus in creating awareness and improving the knowledge level of the refugees about the adherence of iron and folic acid by the government and other supporting agencies. Government and other stakeholders should continue promoting the advantages timely ANC follow up, improve the quality of counseling in ANC service delivery and creating awareness and knowledge about anemia during pregnancy and about the negative perception about IFA drugs.

To minimize or prevent forgetfulness to take the drug, health professionals should counsel the women to correlate taking the drugs with natural events, like sunrise or sun sent, and day-to-day activities, like eating lunch 
or dinner. However, applying calendars are using alarms might not be helpful for these population as most of them are not literate. Regarding fear of side effects, health professionals in charge of giving the IFA drugs should continuously counsel and aware to the respondents that side effects are minor with no or minimum health problem, and if major side effects occurred, they should go to health facilities for management.

\section{Additional files} Additional file 1: A questionnaire used for collecting the quantitative data.
(DOCX $32 \mathrm{~kb}$ )

Additional file 2: A questionnaire used for collecting the qualitative data. (DOCX $19 \mathrm{~kb}$ )

Additional file 3: The minimal anonymized quantitative data used for analysis. (ZIP 17 kb)

\section{Abbreviations}

ANC: Antenatal Care; AOR: Adjusted Odds Ratio; ARRA: Administration for Refugees and Returnees Affairs; COR: Crude Odds Ratio; FGD: Focused Group Discussion; FMOHE: Federal Ministry of Health of Ethiopia; IFA: Iron-Folic Acid; IRC: International Refugee Camp; KIl: Key Informed Interview; WHO: World Health Organization

\section{Acknowledgments}

Our special thank goes to staff members of IRC and ARRA who took part in editing the tool and genuine assistance and devotion from the beginning up to the end of the study.

Our deep appreciation and heartfelt thanks also go to Eritrean refugee pregnant women who participated in this research.

Moreover, we would like to express our gratefulness to the data collectors and supervisors.

\section{Funding}

The principal investigator covers all the costs. There was no another funder.

\section{Availability of data and materials}

The minimal anonymized data is available with this manuscript (See Additional file 3).

\section{Authors' contributions}

$M G, A B, H Z$, and TG (Tirhas) designed the study. MG, $A B, M A, H Z$, and TG (Teklit) analyzed the data, drafted the manuscript and critically reviewed the manuscript. All authors read and approved the final manuscript.

\section{Ethics approval and consent to participate}

Ethical clearance and approval were obtained from the Institutional Review Board of College of Health Sciences of Aksum University. Supporting letters were written by the ARRA head office ethical review committee to ARRA Shire Zonal coordination office and to each camp. The purpose of the study was explained to each study participant, including procedures, potential risks and benefits and verbal consent was obtained from the respondents because most respondents are unable to read and agreed on verbal consent. The institutional review board also approved that verbal consent is enough. Confidentiality of the information was assured and data were collected anonymously.

\section{Consent for publication}

Not Applicable

\section{Competing interests}

The authors declare that they have no competing interests.

\section{Publisher's Note}

Springer Nature remains neutral with regard to jurisdictional claims in published maps and institutional affiliations.

\section{Author details}

${ }^{1}$ Department of Public Health, Aksum University, Aksum, Ethiopia.

${ }^{2}$ Department of Public Health, College of Health Sciences, Aksum University, P.O. Box: 298, Aksum, Ethiopia. ${ }^{3}$ Department of Public Health, College of Health Sciences, Arsi University, Assela, Ethiopia. ${ }^{4}$ School of Public Health, College of Health Sciences, Mekelle University, Mekelle, Ethiopia.

Received: 1 January 2017 Accepted: 23 March 2018

Published online: 05 April 2018

\section{References}

1. McLean E, et al. Worldwide prevalence of anemia, WHO vitamin and mineral nutrition information system, 1993-2005. Public Health Nutr. 2009;12(4):444-54.

2. Badham J, Zimmermann MB. In: Kraemer K, editor. The guidebook nutritional anemia. Basel: Sight and Life; 2007.

3. Central Statistical Agency of Ethiopia. Ethiopia demographic and health survey 2011. Addis Ababa and Calverton: CSA Ethiopia and MEASURE DHS-ICF Macro; 2011.

4. DeMaeyer $E$, Adiels-Tegman M. The prevalence of anemia in the world. World Health Stat Q. 1985;38(3):302-16.

5. Zakia MI, El-Hamid SA, Mikhail H, Maged SK. Assessment of Adherence to Iron and Folic Acid Supplementation and Prevalence of Anemia in Pregnant Women Ismailia governorate. Egypt Med J Cairo Univ. 2011;79(2):115-21.

6. Begum S. Factors associated with adherence to iron folic acid supplementations during pregnancy in Uttar Pradesh. Indian J Matern Child Health. 2012;14(2):8.

7. Sengpiel $V$, et al. Folic acid supplementation, dietary folate intake during pregnancy and risk for spontaneous preterm delivery: a prospective observational cohort study. BMC Pregnancy Childbirth. 2014;14:375.

8. Ogundipe $\mathrm{O}$, et al. Factors associated with prenatal folic acid and iron supplementation among 21,889 pregnant women in northern Tanzania: a cross-sectional hospital-based study. BMC Public Health. 2012;12:481.

9. Federal Ministry of Health (FMOH) of Ethiopia. A a national guideline for control and prevention of micronutrient deficiencies. Addis Ababa: $\mathrm{FMOH} ; 2004$.

10. World Health Organization (WHO). Iron deficiency anemia assessment, prevention, and control. Geneva: WHO press; 2010.

11. Allen LH. Anemia and iron deficiency: effects on pregnancy outcome. Am J Clin Nutr. 2000;71(5 Suppl):1280S-4S.

12. Abdullahi $\mathrm{H}$, et al. Antenatal iron and folic acid supplementation use by pregnant women in Khartoum, Sudan. BMC Res Notes. 2014;7:498.

13. World Health Organization (WHO). Weekly iron-folic acid supplementation (WIFS) in women of reproductive age: its role in promoting optimal maternal and child health. Position statement. Geneva: WHO press; 2009.

14. Gebre A, Mulugeta A. Prevalence of Anemia and associated factors among pregnant women in north western zone of Tigray, northern Ethiopia: a cross-sectional study. J Nutr Metab. 2015;2015:165430.

15. Gebremedhin S, et al. Coverage, compliance and factors associated with utilization of iron supplementation during pregnancy in eight rural districts of Ethiopia: a cross-sectional study. BMC Public Health. 2014;14:607.

16. Mithra $P$, et al. Compliance with iron-folic acid (IFA) therapy among pregnant women in an urban area of South India. Afr Health Sci. 2014;14(1):255-60.

17. Ugwu EO, et al. Determinants of compliance to iron supplementation among pregnant women in Enugu, southeastern Nigeria. Niger J Clin Pract. 2014;17(5):608-12.

18. Seck BC, Jackson RT. Determinants of compliance with iron supplementation among pregnant women in Senegal. Public Health Nutr. 2008;11(6):596-605.

19. Lustsey PL, et al. Iron supplementation compliance among pregnant women in Bicol, Philippines. Public Health Nutr. 2007;11(1):76-82.

20. Taye B. Factors associated with compliance of prenatal iron-folate supplementation among women in Mecha district, western Amhara: a cross-sectional study. Pan African Medical Journal. 2015;20(43)

21. Sanghvi TG, Harvey PWJ, Wainwright E. Maternal iron-folic acid supplementation programs: Evidence of impact and implementation. Food Nutr Bull. 2014;31(8):100-7.

22. Mei Z, Cogswell ME, Looker AC, Pfeiffer CM, Cusick SE, Lacher DA, et al. Assessment of iron status in US pregnant women from the National Health and nutrition examination survey ( NHANES ), 1999 - 20061 - 4. Am J Clin Nutr. 2011;6(93):1999-2006.

23. Tong A, Sainsbury P, Craig J. Consolidated criteria for reporting qualitative research (COREQ): a 32-item checklist for interviews and focus groups. Int J Qual Health Care. 2007;19(6):349-57. 